$\xi=-1$

\title{
Tensile and Fatigue Behaviour of Glass Fibre Reinforced Polyester Composites
}

\author{
Roy Hanson Jimit ${ }^{1}{ }^{*}$, Kamarul Ariffin Zakaria $^{1}$, Omar Bapokutty $^{1}$ and Sivakumar Dhar Malingam ${ }^{1}$ \\ ${ }^{I}$ Faculty of Mechanical Engineering, Universiti Teknikal Malaysia Melaka \\ 76100 Hang Tuah Jaya, Durian Tunggal, Melaka, Malaysia \\ *Corresponding author E-mail: royhanson.jimit@yahoo.com :
}

\begin{abstract}
This document contains the formatting information for the papers presented at the International conference on " 4 th International Conference on Recent Advances in Automotive Engineering \& Mobility Research (ReCAR IV)". The conference would be held at Hotel Bangi-Putrajaya during August 8-10, 2017. Fibreglass composites are one of the materials that can be used in manufacturing of the vehicles part due to their excellent lightweight properties. Composite structures may undergone the fatigue failure when subjected to a certain numbers of cyclic loading, which is normally occurs below the ultimate strength of material. However, there still lack of studies on the effect of fibre orientations on the fatigue strength of glass fibre reinforced composites (GFRC). Therefore, the purpose of this study is to determine which orientation would have the highest fatigue strength. The fibre materials used in this study is unidirectional glass fibre with $[0 / 90]^{\circ},[ \pm 45]^{\circ}$ orientation and chopped strand mat (CSM). The composite is fabricated from glass fibre and polyester resin using a hand lay-up technique according to ASTM D3039 for tensile test and ASTM D3479 for fatigue test. The results were presented in the form of S-N curve. The results show that the mechanical properties and fatigue behavior were significantly affected by the fibre orientation of the GFRC
\end{abstract}

Keywords: Glass fibre reinforced composite; Fibre orientation; Fatigue life; Mechanical properties; Tensile.

\section{Introduction}

Composite materials are characterized as materials which comprise of a blend of at least two materials that outcome in preferable properties over those of the individual materials [15]. The properties that overcome most of the isotropic material in term of their high strength and stiffness and low density make fibre reinforced composites a very recommended materials [18]. The desire of production in bulk and lower production cost has made the fibrereinforced composites are now widely accepted as structural materials within the aerospace and automotive industries. The increment of using fibre reinforced composites due to their fast fabrication processes, high damage tolerance and high chemical and environmental resistance allow this composites material to replace the current isotropic material in industries [8, 12].

In previous years, few researches have focused on composite materials especially the glass fibre to determine the fatigue strength and failure mechanisms of the material. There a few factors that affect the behavior of the material which due to the material design and environment effects $[2,5]$. The material properties and the fatigue behaviour also affected by the loading rate, mean stress, load frequency, thickness, fibre volume and fibre orientation of the composite lamina [7, 9, 13, 14, 17].

Fatigue also occurred in composites such as metal and other elements. Fatigue is defined as the damage of materials when subjected to cyclic loading which occurred below the ultimate tensile strength of the material. The mechanical properties of the material will be degraded when subjected to fatigue loadings [20, 21].
Therefore, the fatigue damage can be enhanced by improving the interlaminar properties which include the fibre orientation [11]. There are previous studies been done on the influence of fibre orientation and thickness on tensile properties of laminated woven glass fibre reinforced composites [13]. Research found that fibre aligned in specific orientation have different mechanical strength when compare to discontinuous and randomly oriented [6]. Another research found that the material's behavior of the composites are affected by the orientation of each layer [16]. The different orientation of fibre alignment has significant effect on the damage mechanism of a composite material [1].

This motivates the current work to conduct a study on the effect of fibre orientation on mechanical properties of GFRC with different type of glass fibre which are unidirectional glass fibre and chopped strand mat (CSM). In this experimental study, the fibre orientations tested were $[0 / 90]^{\circ}$ and $[ \pm 45]^{\circ}$ and a chopped strand mat (CSM). The samples for the tensile test and fatigue test were fabricated using the hand lay-up technique and tested on an Instron 8872 Universal Testing Machine. The fibre orientation was analyzed experimentally, and its relationship with the observed fatigue life was investigated.

\section{Methodology}

A Hand Lay-up technique is use for composite fabrication. A unidirectional glass fiber with orientation of $[0 / 90]^{\circ},[ \pm 45]^{\circ}$ and chopped strand mat (CSM) is chosen to study the effect of the orientation. Polyester resin with hardener was used for the matrix. The fiberglass were cut out into size of $30 \mathrm{~cm} \times 30 \mathrm{~cm}$ as shown in Figure 1, with four pieces for each composite. 


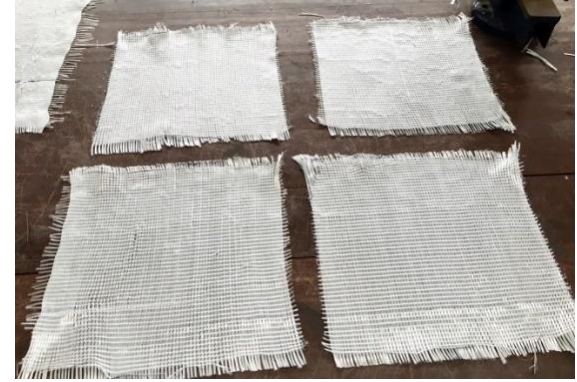

Fig. 1: Specimen cut into required size of $30 \mathrm{~cm} \mathrm{X} 30 \mathrm{~cm}$

Polyester resin and hardener were mixed with weight ratio of 5:1, that is 5 gram of resin per 1 gram of hardener. After the mixing process of matrix material, then the mixture was applied to the mat. The laminates were fabricated by placing the glass fiber one over the other with a matrix in between the layers. Roller was used during the fabrication process to eliminate air bubbles. The same procedure were carried out for all four mats for each composite. Finally, the laminates were cured in room temperature for 2 days to make sure the resin between each ply was completely dry before removing the composite from the wooden frame as shown in Figure 2.

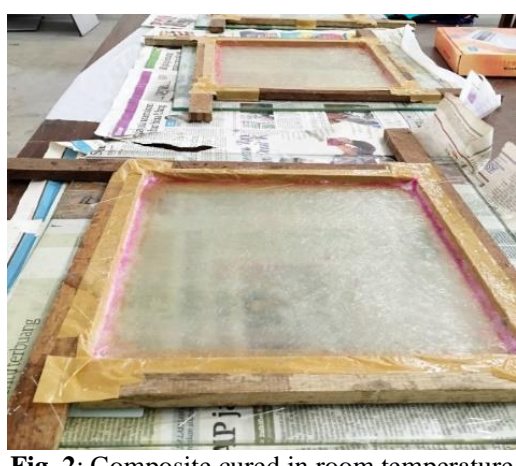

Fig. 2: Composite cured in room temperature

After fabrication the test specimens were subjected to tensile test and constant amplitude fatigue test using a Universal Testing Machine, Instron 8872. The specimens were cut to meet the specifications as shown in Figure 3 of ASTM D3039 for tensile test that operated at constant head-speed tests of $5 \mathrm{~min} / \mathrm{mm}$ and ASTM D3479 for fatigue test that was conducted under constant amplitude loading (CAL) using a sine wave at $1.0 \mathrm{~Hz}$ frequency and stress ratio, $\mathrm{R}=0.1$.

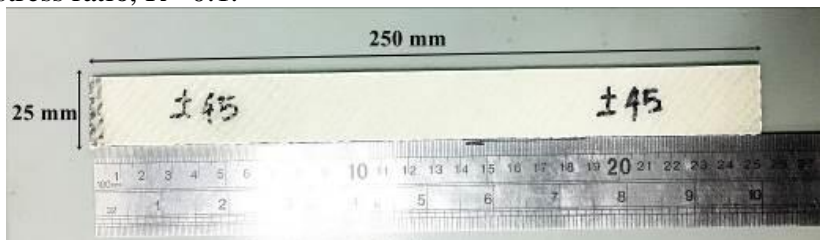

Fig. 3: Standard tensile test specimen dimensions as per ASTM D3039 and ASTM D3079

\section{Results and Discussion}

\subsection{Static Loading}

Figure 4 shows a graph plotted of the stress versus strain. This stress-strain curve shows that the strength and the ductility of the materials. The results showed the mechanical properties are obviously affected by the fiber orientation as each sample shows different value of Ultimate Tensile Strength (UTS), Modulus of Elasticity $(\mathrm{E})$ and Ultimate Tensile Strain $\left(\varepsilon_{\mathrm{ult}}\right)$. The results then tabulated in Table 1.

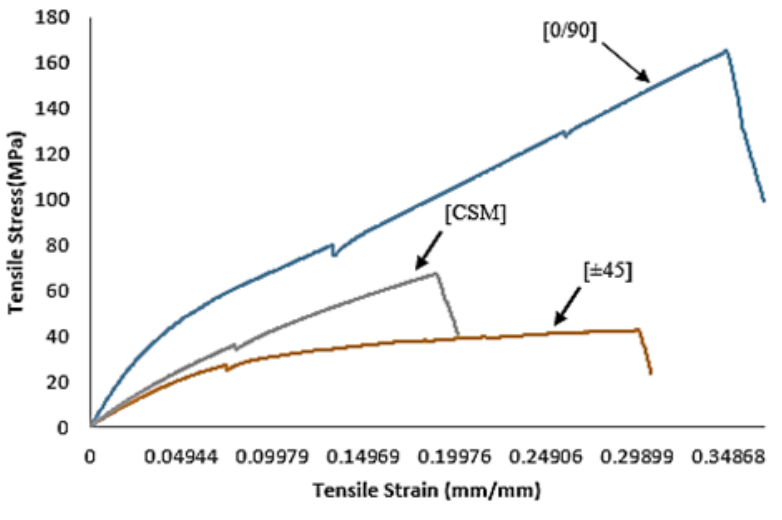

Fig. 4: Typical stress-strain curve for the tensile tests

Table 1 show the tabulation of results from the tensile test of unidirectional glass fibre reinforced composite with orientation of $[ \pm 45]^{\circ}$ and $[0 / 90]^{\circ}$ and chopped strand mat (CSM). The value shown are the average value for each tested sample.

Table 1: The average value of mechanical properties of GFRC with different fibre orientations and CSM

\begin{tabular}{|l|l|l|l|}
\hline $\begin{array}{l}\text { Orientations } \\
\left({ }^{\circ}\right)\end{array}$ & $\begin{array}{l}\text { UTS } \\
\text { MPa }\end{array}$ & $\begin{array}{l}\text { Eult } \\
\text { Mm/mm }\end{array}$ & $\begin{array}{l}\text { Modulus E } \\
\text { MPa }\end{array}$ \\
\hline$\left[ \pm 45^{\circ}\right]$ & 40.7 & 0.18 & 713.9 \\
\hline$\left[0 / 90^{\circ}\right]$ & 166.2 & 0.21 & 1947.7 \\
\hline CSM & 71.6 & 0.11 & 995.2 \\
\hline
\end{tabular}

It shows that $[0 / 90]^{\circ}$ orientation has the highest mechanical strength compared to CSM and $[ \pm 45]^{\circ}$ orientation. The UTS value which mean the capacity of the GFRC to withstand load before fracture, showed that $[0 / 90]^{\circ}$ is the highest with $166.2 \mathrm{MPa}$. Table 1 above shows that $[0 / 90]^{\circ}$ has the highest value $(0.21)$ of $\varepsilon_{\text {ult }}$ compare to CSM and $[ \pm 45]^{\circ}$ orientation, this indicates that the sample can elongate more before reaching the plastic region. The same trend was also observed for the Young's modulus, E the highest value is at $[0 / 90]^{\circ}$ with $1947.7 \mathrm{MPa}$. This indicated that $[0 / 90]^{\circ}$ orientation more elastic compare to CSM and $[ \pm 45]^{\circ}$ orientation. Data from Figure 4 and Table 1 shows that $[0 / 90]^{\circ}$ orientation have a higher mechanical properties compared to $[ \pm 45]^{\circ}$ orientation and CSM due to the fibre alignment in longitudinal direction that give the samples much resistance against loading occurs in the shell layers of the composite. This lead to tensile properties in the longitudinal direction is greater, as compared with in the transverse direction. The strengths of continuous and unidirectional fibrous composites are highly anisotropic, and such composites are normally designed to be loaded along the high strength, longitudinal direction. However, during in-service applications transverse tensile loads may also be present. In this situation, early failure may occur as transverse strength is usually extremely low, it sometimes lies below the tensile strength of the matrix (Seyyedvahid et al. 2015; Chawla 1998). This finding is in accordance with other research finding that show the sample with orientation in longitudinal fiber alignment is stronger compared to orientation in transverse fiber alignment in term of mechanical properties (Torabizadeh 2013; Prashant et al. 2012; Hussain et al. 2012).

From the value of UTS from each sample, fatigue test was conducted by selecting the percentage of the UTS value for constant amplitude loading (CAL). The fatigue results of the specimens are reported in Figure 5, a semi-log plot of the stress amplitude versus the number of cycles to failure. This $S-N$ curve shows that fatigue life generally increases with decreasing cyclic stress amplitude. The $S-N$ curve was developed using curve fitting of tabular data according to the Basquin equation, which can be written as in (1).

$\sigma a=(N f)^{b}$ 
where $\sigma_{a}$ is the stress amplitude, $a$ and $b$ are the material constants, and $N_{f}$ is the number of cycles to failure (Zakaria et al. 2013).

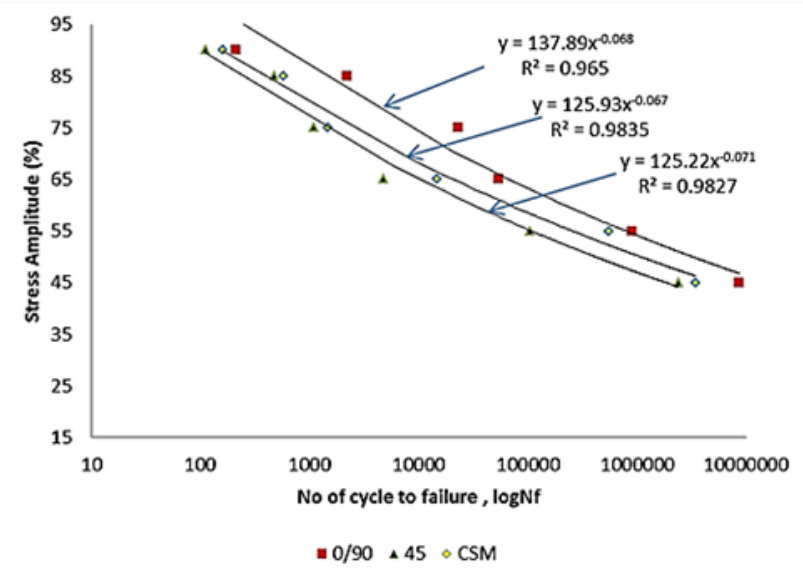

Fig. 5: Comparison of the number of cycles to failure for the different GFRC sample.

It is noticed that the number of cycle to failures is the greatest in $[0 / 90]^{\circ}$ orientation compared to CSM and $[ \pm 45]^{\circ}$ orientation. By looking at 3 points of stress amplitude (\%), the trend of fatigue behaviour can be understood. At $90 \%$ UTS (high load), the S-N curve shows that $[0 / 90]^{\circ}$ orientation has the highest fatigue strength with 212 cycles before failure, followed by CSM with 160 cycles before failure and the lowest number of cycle before failure is shown by $[ \pm 45]^{\circ}$ orientation with 113 cycles. At $65 \%$ UTS, the S-N curve showed that $[0 / 90]^{\circ}$ orientation has the highest fatigue strength with 54021 cycles before failure, followed by CSM with 14831 cycles before failure and the lowest is $[ \pm 45]^{\circ}$ orientation with 4743 cycles before failure. At 45\% UTS (low load), the $\mathrm{S}-\mathrm{N}$ curve shows that $[0 / 90]^{\circ}$ orientation has the highest fatigue strength with 8548264 cycles before failure, followed by CSM with 4429129 cycles before failure and the lowest is $[ \pm 45]^{\circ}$ orientation with 2383652 cycles before failure. Fatigue life was found to be the longest in $[0 / 90]^{\circ}$ orientation, whereas the shortest was observed in $[ \pm 45]^{\circ}$ orientation.

\section{Conclusion}

In this study, the effect of the correlation between the fiber orientation and the fatigue behavior of FGRC was investigated. The strength of GFRC are presented in both tensile and fatigue test. In summary the findings provide insights that fatigue life is influenced significantly by mechanical properties of GFRC, where the fatigue strength is increased with the increment of UTS value of GFRC. It also found that the GFRC $[0 / 90]^{\circ}$ orientation has the highest mechanical properties and fatigue strength compared to $[ \pm 45]^{\circ}$ and $[\mathrm{CSM}]$. The highest number of cycles to failure for GFRC with $[0 / 90]^{\circ}$ orientation compared to those with $[ \pm 45]^{\circ}$ orientation and CSM mainly due to the fibre alignment in longitudinal direction of the composite.

\section{Acknowledgement}

Authors would like to thank ministry of higher education of malaysia and universiti teknikal malaysia melaka (utem) for providing support and financial assistance under grant $\mathrm{frgs} / 2 / 2014 / \mathrm{tk} 01 / \mathrm{fkm} / 03 / \mathrm{f000234}$ and grant rags/1/2014/tk01/fkm/b00068.

\section{References}

[1] Bernasconi A, Davoli P, Basile A, Filippi A. Effect of fiber Orientation on The Fatigue Behaviour of A Short Glass Fiber Reinforced Polyamide-6. International Journal of Fatigue, (2007), 29, 199-208.
[2] Case S, Reifsnider KL, Fatigue of Composite Material. In: Milne I, Karihaloo B, Eds. Comprehensive Structural Integrity: Cyclic Loading And Fatigue, Oxford: Elsevier Ltd, (2012), 57-59.

[3] Chawla K, Composite Material Science and Engineering, $2^{\text {nd }}$ edition, New York: Springer-Verlag, (1998), 141-147.

[4] Dicka TM, Jar PB, Cheng JR. Prediction of Fatigue Resistance of Short-Fiber Reinforced Polymers. International Journal of Fatigue, (2009), 31, 184-191.

[5] Frederic C, Introduction to Composite Material:Structural Composite Material, $1^{\text {st }}$ edition, Ohio: ASM International, (2010), 16-59.

[6] Hussain JA, Dhafir S, Al-Fattal AJ, Ali H. Type of The Fiber Glass Mat on Fatigue Characteritic of Composite Materials at Constant Fiber Volume Fraction: Experimental Determination. Al-Khwarizmi Engineering Journal, (2012), 8(3), 1-12.

[7] Khan AS, Colak OU, Centala P. Compressive Failure Strengths and Modes of Woven S2-Glass Reinforced Polyester Due to QuasiStatic and Dynamic Loading. International journal of Plasticity, (2002), 18(10), 1337-1357.

[8] Kumagai S, Shindo Y, Inamoto A. Tension-tension fatigue behaviour of GFRP laminates at low temperature. Cryogenics, (2005), 45(1), 123-128.

[9] Mallick PK, Yuanxin Z. Effect of Mean Stress on Stress-Controlled Fatigue of Short E-Glass Fiber Reinforced Polyamide-6. Int J Fatigue, (2004), 26(6), 941-946.

[10] Mohammad AT. Tensile, Compressive and Shear Properties of Unidirectional Glass/Epoxy Composite Subjected To Mechanical Loading and Low Temperature Services. Indian Journal of Engineering and Material Sciences, (2013), 20, 299-309.

[11] Mouritz KL, Herszberg I. A Review of the Effect of Stiching in the in-Plane Mechanical Properties of Fiber Reinforced Polymer Composites. Composites:Part A, (1997), 28(12), 979-991.

[12] Pandita SD, Huysmans G, Wevers M, Verpoest I. Tensile fatigue behaviour of glass plain-weave fabric composites in on-and-off-axis directions. Composites: Part A, (2004), 32, 1533-1539.

[13] Prashanth B, Shivananda HK, Niranja HB. Influence of Fiber Orientation and Thicnkness on Tensile Properties of Laminated Polymer Composites. International Journal of Pure Applied Sciences and Technology, (2012), 9(1), 61-68.

[14] Rahman MM, Jeffrey KT. Residual Strength of Chop Strand Mat Glass Fiber/Epoxy Composite Structures: Effect of Temperature and Water Absorption. International journal of Automotive and Mechanical Engineering, (2011), 4, 504-519.

[15] Sabu T, Kuruvilla J, Malhotra SK, Koichi G, Sreekala MS. Polymer Composites:Macro and microcomposites, $1^{\text {st }}$ edition, Weinheim, Germany: Wiley-VCH Verlag GmbH \&Co. KGaA, (2012), 64-109.

[16] Seyyedvahid M, Ali F. Effect of Fiber Orientation and Anisotropy on Tensile Strength and Elastic Modulus of Short Fiber Reinforced polymer Composites. Composites, (2015), 72(B), 116-129.

[17] Sutherland LS, Soares CG. Impact on Low Fiber-Volume, Glass/Polyester Rectangular Plates. Composite Structures, (2005), 68(1), 13-22.

[18] William DC, Materials Science and Engineering, An Introduction, $7^{\text {th }}$ edition, John Wiley And Sons, Inc, (2007), 158-163.

[19] Zakaria KA, Abdullah S, Ghazali MJ. Elevated Temperature Fatigue Life Investigation of Aluminium Alloy based on the Predicted S-N Curve. Jurnal Teknologi, (2013), 63(1), 75-79.

[20] Zakaria KA, Abdullah S, Ghazali MJ. A Review of the Loading Sequence Effects on the Fatigue Life Behaviour of Metallic Materials. Journal of Engineering and Technology Review, (2016), 9(5), 189200.

[21] Zakaria KA, AbdullahS, Ghazaki MJ, Azhari CH. Influence of spectrum loading sequences on fatigue life in a high-temperature environment. Engineering Failure Analysis, (2013), 30, 111-123. 